\title{
Travelling Across America in One Place: The Phenomenon of the Interstate Village
}

\author{
Alf Simon \\ School of Architecture and Planning, University of New Mexico, United States
}

Copyright $\bigcirc 2016$ by authors, all rights reserved. Authors agree that this article remains permanently open access under the terms of the Creative Commons Attribution License 4.0 International License

\begin{abstract}
This paper focuses on one particular landscape that has evolved within the interstate highway system: the interstate village - defined here as a commercial node at a non-metropolitan interchange where the interstate passes within a mile or two of a town. There have been a number of localized studies done on non-metropolitan interchanges related to economic development and land use change, and to a small degree in the context of central place theory. However, there has been very little attention and study devoted to the Interstate village in a cultural context as 'place', and on the phenomenon as an emerging urban type. This study asks whether interstate villages, regardless of regional location, exhibit strong common physical and compositional characteristics as a part of the interstate system, while also reflecting more subtle local or regional identities through their town attachments. Fourteen interstate villages at non-metropolitan interchanges were studied on a sample transect along I-70 from Denver, CO to New Stanton, PA. The findings from this one sample transect indicate that there is a striking spatial and cognitive similarity among the villages, and sameness in visual character. There is some morphological pattern variation in the villages, and very little regional or local expression.
\end{abstract}

Keywords Urban Design, Cultural Landscape,
Interstate Village

\section{Introduction}

With the passage of the 1954 Federal-Aid Highway Act, championed by the Eisenhower administration, the US began building what is arguably the most extensive and ambitious infrastructure system in the country. With almost 50,000 miles of interstate highway oriented in north-south and east-west corridors, the interstate system forms a network of movement over the entire continental US. This system not only manifests itself physically on the landscape, but also reaches into the political, economic and cultural cores of society. In many ways this system that embodies movement, accessibility, freedom, commerce and politics is a landscape of the collective culture and represents who we are as a nation.

\section{Background}

The history of the Interstate highway system has been well documented (for example, Moon, Lewis, McNichol, Perrier, Murphy [1-5]). The interstate system has also been studied in many disciplines (economics, geography, political studies, transportation, engineering, sociology), each bringing a different perspective to the workings and impacts of this phenomenon. The research project that is the subject of this paper focuses on one particular part of the interstate landscape that has evolved within the system: the interstate village. The interstate village is defined in this study as a commercial node at a non-metropolitan interchange where the interstate passes within a mile or two of a town. The interstate village is an ambiguous landscape - it is a part of the identity of the interstate system, but is also associated with the adjacent town.

Roadway design tends to subscribe to unified standards that address issues of safety and function, and in that sense each road type has common characteristics. Roadway dimensions, interchange types, median types and signage design are definable elements that contribute strongly to the identity and character of the interstate system. The interstate villages typically develop at non-metropolitan interchanges where the interstate, having usually replaced a highway that ran through a town, now passes within a mile or two of a town. They are service-based, normally comprised of motels, restaurants, gas stations and truck stops. In most cases the businesses are dominated by corporate chains. Residents of the adjacent towns work at the various interstate village businesses, and increasingly, residential development in the towns is edging closer to the villages. In many cases a highway strip development connects the town and the Interstate village.

A number of studies, mainly localized, have been carried out on various aspects of non-metropolitan interchanges (the 
commonly-used term). It appears that the Interstate system and the development of interchange villages has had a positive impact on the economy of rural areas in North America (for example, Moon, Boarnet, Gambel et al, Twark, Cribbins et al [6-10). Moon [6] studied interstate villages in Kentucky and discussed the growth and development of some of the villages in terms of Christaller's central place theory. In these cases the interstate village has become more than a commercial service node for travelers; it has expanded into a center serving a regional population with shopping centers, car dealerships and similar businesses that address the needs of a regional geographic area. Studies on land use change (Moon, [6] Briggs, Everly et al, Humphrey and Sell, , Theil [11-14]) show that there has been rapid and intense change in land use at interchanges, including the introduction of an array of commercial uses, industrial development located to take advantage of the proximity of the interstate, some institutional uses, and even residential development at the margins of some villages. Studies also show that interchange development has produced environmental impacts with degradation to the ecological profile of these landscapes. Norris [15] studied interchanges along I-75 to assess whether there are morphological similarities in the villages. He identified five basic village forms, and his study focused largely on the types and distribution of businesses in the villages. He noted that most businesses are located within a half mile of the interchange, and that the villages tend to sprawl unnecessarily. Norris also addressed the issue of generic and regional character of the villages, and concluded that the presence of some local businesses indicated regional flavor.

A study of planning and development guidelines for non-metropolitan interchanges in Vermont (Vermont Department of Housing and Community Affairs [16]) identified a number of issues related to the growth of Vermont interchanges, including:

- a growth pattern that is becoming increasingly dispersed

- the need for expensive infrastructure at the villages, particularly sewer and water

- conflict with businesses and services in the towns

The Vermont study also identified an opportunity for the interstate villages to serve as gateways into the towns. In his conclusion, Moon [6] posited several questions that he feels need to be addressed in studying interstate villages:

"Does Interchange morphology resemble that of many small towns where commercial and other development occurred at more important crossroads? How will already understaffed rural law enforcement agencies meet the legal needs of interchange villages? Because each of the villages exists in an area without any form of zoning or land use regulation, will conflict arise between land users with contradictory goals? How will future infrastructure requirements of interchange villages be met?"

There has still been little attention and study devoted to the Interstate village in a cultural context as 'place' and on the 'village' phenomenon as an emerging landscape.

Human settlements can be studied in a typological framework. In a general sense, we can categorize urban settlements into those that have been planned, and those that have not. Settlements that were planned in accordance with strong political, cultural and/or social value systems (for example, Roman towns, the Laws of the Indies), by technological and/or economic imperatives (for example, the railway towns in North America) industrial systems (for example, the factory town) or by regulatory systems (for example, the North American suburb), tend to subscribe to principles that attempt to achieve ideal or efficient form in the context of the principles by which they were generated. Although ideal form is rarely achieved, settlements developed under such regimes exhibit patterns that have very strong morphological similarities to each other. Roman towns, for example, were largely based on the principle of the Roman castrum, or military settlement. This layout was a grid spread over a slightly rectangular area that featured two main orthogonal roads called cardus and decumanus. The gridded town was surrounded by a defensive wall with four gates located at the ends of each of the two main axis roads. The buildings and spaces of social and religious life were placed at or near the intersection of the main roads (Haverfield [17], Magli [18]).

The North American railway town was generated both by a transportation network and a corporate desire to control territory and land, and to take advantage of regional business opportunities. While maintaining a rigid grid layout the form of the railway town evolved to find the best fit between commerce and the railway connection. Ultimately, a $\mathrm{T}$ layout with the railway tracks and station on one side of the town and the main street at a right angle to the track, was the most acceptable solution (Figure 1). Of course it would be unusual to find two towns of the same type category that are morphologically identical. In spite of a strong guiding rationale that would have informed the layout, each town would exhibit differences based on geographic location, topographic conditions, and the inhabitants. The interstate village appears to be born out of a technological/economic framework, and notwithstanding inevitable differences it is reasonable to think that it can be defined as a distinct type with common formal characteristics

One of the interesting aspects of the interstate highway system is that the corridors pass through landscapes, but remain separate from them. They are on the landscape but not in it; they are a landscape within a landscape. The entire system itself occupies space but has no discrete, contained geographical location. Is the interstate a place? Can we say that interstate villages are places? The literature on 'place and 'sense of place' is complex and varied, and a robust discussion of whether the interstate village is or is not 'place' is the subject of another paper, at very least. However, it is important to acknowledge this debate, and to consider whether 'placelessness' can be an accepted, and perhaps even an important, part of our geographical experience. Relph [19] described “a 'placeless geography' in which 
different localities both look and feel alike, and in which distinctive places are experienced only through superficial and stereotyped images and as indistinct and unstable backgrounds to our social and economic roles" (p. 118). Kunstler [20] bemoans the loss of place saying that "Eighty percent of everything built in America has been built in the last fifty years, and most of it is depressing, brutal, ugly, unhealthy and spiritually degrading....." (p. 10). These descriptions certainly appear to fit both the interstate system and the interstate village. On the other hand, J.B. Jackson [21] asserts that "Roads no longer merely lead to places; they are places. And as always they serve two important roles: as promoters of growth and dispersion, and as magnets around which new kinds of development can cluster. In the modern landscape no other space has been so versatile" (p. 251). In spite of morphological similarities and sameness based on their common foundation of economic ideology, railway towns and other similar ideologically planned settlements seem to have established individual identities as places. They have names, and over time they develop unique character in response to regional patterns and the cultural norms of the inhabitants. Interstate villages frequently fall within the boundaries of the adjacent town, and are identified both with the town name and by the interstate exit number. As we will see they all look very much the same from region to region, with the same businesses, the same architecture, the same spatial character and the same general morphology. Normally there are no residents in the interstate villages, depending on how one defines the boundaries. People work in the businesses of the villages, and travelers stop for ten minutes to buy gas, an hour to eat, a few hours at the mall if it happens to be a regional center, or for an overnight stay in a hotel. The villages are, however, important nodes along and within the interstate system that provide critical services for travelers and that contribute to regional commerce and the regional economy.

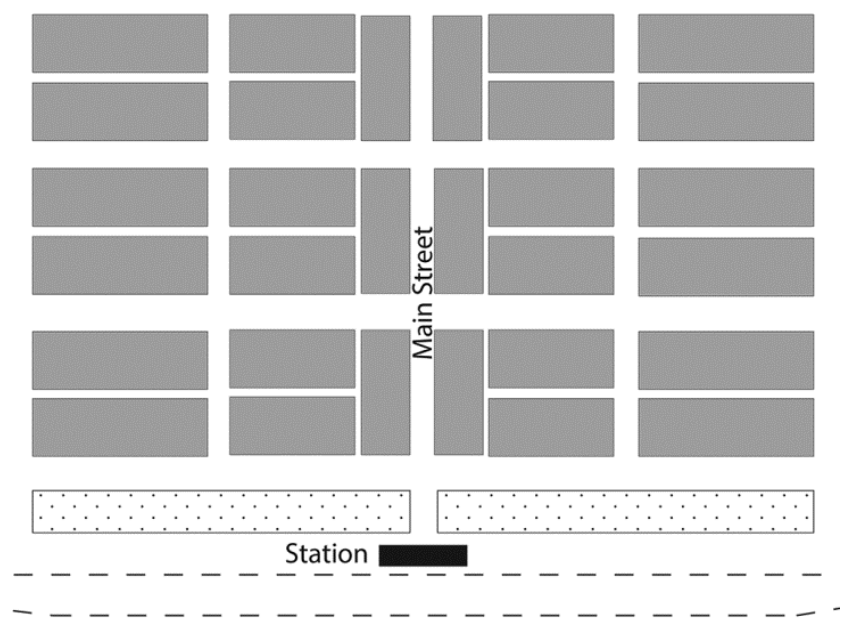

Figure 1. Typical $\mathrm{T}$ layout of a railway town. Drawing by author
The general hypothesis driving this study is that the interstate villages, regardless of regional location, exhibit strong common spatial and compositional characteristics generated by the conditions of the interstate system, and that as a 'settlement' type there are components that uniquely define the interstate village. There is also a question about whether interstate villages reflect more subtle local or regional identities through their town attachments.

The intention of this study was to sample a selection of interstate villages in order to understand whether the hypothesis has validity and whether the question of regional character can be pursued in a larger study covering more regions. The method used for the study is as follows:

Non-metropolitan interchanges were studied on a sample transect along I-70 from Denver, CO., to New Stanton, PA., where the Pennsylvania Turnpike begins. I-70 was the first Interstate Highway project in the United States, and is the fifth longest Interstate stretching from I-15 near Cove Fort, Utah, to Baltimore, Maryland. I-70 crosses ten states: Utah, Colorado, Kansas, Missouri, Illinois, Indiana, Ohio, West Virginia, Pennsylvania and Maryland. The study transect enters all but two of these states, Utah and Maryland, and represents approximately 1,700 miles of interstate that covers parts of four identifiable regions: the edge of the mountain west, the great plains, the mid-west and the north east.

Prior to traveling this route, sample interstate villages were identified by doing a virtual journey on Google Earth. The villages identified were typically ones that have emerged at non-metropolitan interchanges that are one half mile to two miles from a town near the interstate. Ten villages were selected for the target sample and four more were added in the field. The town populations range from 2000 to 19,000 (Table 1).

Table 1. Sample Villages

\begin{tabular}{llll}
\hline Town & State & Pop. & $\begin{array}{l}\text { Regional } \\
\text { Center }\end{array}$ \\
\hline Limon & CO & 2,071 & \\
Burlington & CO & 3,678 & \\
Goodland & KS & 1,948 & \\
Russell & KS & 4,696 & \\
Colby & KS & 5,030 & \\
Junction City & KS & 18,886 &. \\
Boonville & MO & 8,319 & \\
Warrenton & MO & 7,398 & g \\
Effinham & IL & 12,384 & \\
Marshall & IL & 3,771 & \\
Cloverdale & IN & 2,172 & \\
Cambridge & OH & 11,520 &. \\
St. Clairsville & OH & 5,057 &.
\end{tabular}

The approach to studying the villages was qualitative, based on observation using a set of assessment variables that were developed to reflect components of a town/village

\section{The Study}


landscape. Each of the fourteen villages were observed in accordance with the following attributes:

\section{Cognitive Qualities/Announcement}

How does the village establish presence from a distance across the landscape, and how does the village convey function and wayfinding?

\section{Spatial Organization/ Morphology}

What is the layout/compositional pattern of the village? Is there a typical layout pattern for interstate villages that can be identified and are there standard variations on the layout?

\section{Spatial Character}

How is the village perceived in terms of scale, transitions and spatial character of the landscape?

\section{Regional Expression}

Is local or regional character manifest in the villages and, if so, in what ways?

The observations for each village were recorded in notes and photographic documentation, and with figure-ground plans that indicate grain, density, composition and circulation. As a follow-up, town managers were contacted and surveyed with a standard list of open-ended questions.

\section{Observations and Findings}

\subsection{Cognitive Qualities/Announcement}

One of the characteristics of human settlements is the manner in which they announce their presence at different scales within the landscape, placing themselves in the consciousness of observers. At the larger landscape scale verticality is the primary device. As you look across the landscape what is it that signals the presence of a human settlement? In cities we see the cluster of downtown high-rise buildings from a great distance. Towns and villages frequently signal themselves with church spires and water towers. Agricultural towns might have tall silos or grain elevators. Industrial centers will have smokestacks. Increasingly, one of the prominent vertical icons of settlement is the cell phone tower. Interstate villages certainly are announced by a gallery of billboards along the interstate that start a considerable distance away, but the villages have their own unique vertical icon - the pylon sign. These are commercial signs for interstate village businesses mounted on top of poles that can be over one hundred feet high, and are visible from a great distance on the interstate. While a single pylon sign might get lost on the horizon, interstate villages are usually announced by a forest of pylon signs, beckoning the traveler from afar to exit the interstate corridor with the promise of food, fuel or lodging (Figure 2). Once in the villages, extensive signage is the main device for information and navigation, rather than more subtle cognitive strategies that characterize good urban design. The signage at this scale is in the form of highway strip signs pole signs or other free standing sign constructions, approximately fifteen to twenty feet high, designed to be read from a vehicle moving at thirty five or forty miles per hour. In this sense, the urban villages are very straight-forward landscapes - what you see is what you get. There is very little left to the imagination, interpretation or to curiosity, and they do not purport to be anything more than a collection of services.

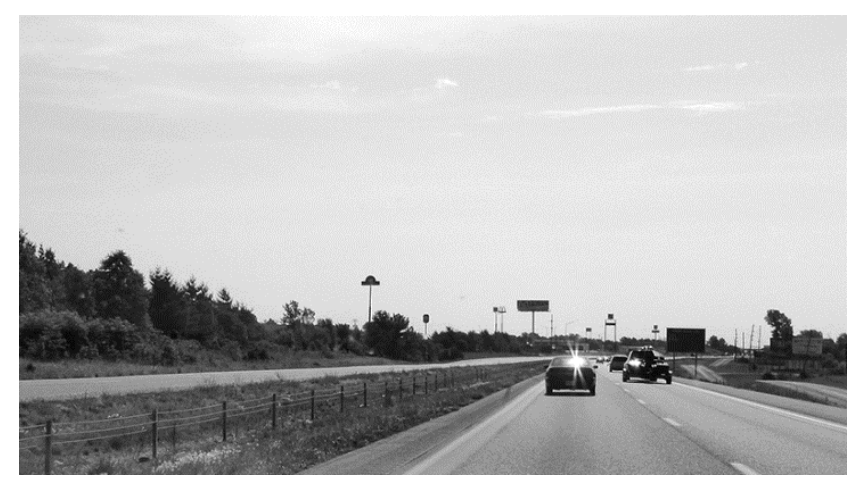

Figure 2. Pylon signs outside Warrenton, MO. Photo by author

\subsection{Spatial Organization/ Morphology}

As discussed above, most planned settlement landscapes incorporate layouts designed to maximize the physical manifestation of the principles on which they were founded. Most planned settlements also have a rational form based on an orthogonal geometry that has been fit onto a local topography. Norris five basic forms and three hybrid forms from his study of exits on I-75, and the results of this study, both reveal that the primary morphological characteristic common to interstate villages is a linear composition with one major axis as the spine. The wide axis road is normally perpendicular to the interstate and leads into the adjacent town. There are some conditions that give variation to this basic form. Interstate village development may occur only on the town side of the interstate (Figure 3), or it may occur on both sides (Figure 4). Development tends to lean more heavily to the town side, with newer development occurring across the interstate. There may be one or more smaller access roads that run perpendicular to the main axis, sometimes extending across the axis and sometimes on just one side. These roads generate a rib formation and do not develop into a full grid pattern. The number of perpendicular or cross roads depends on the size of the adjacent town and hence the popularity of the interstate village as a stopping point (Figure 5). If the interstate village serves as a regional center it will be more spread out, with regional businesses such as a mall, a Walmart, a theatre complex or a large DIY store, and these may be located along the main axis, or along a service road parallel to the interstate (Figure 6). Although the overall axial composition seems to be simple, circulation is surprisingly awkward. The main axis road sometimes has service roads running parallel on each side and village businesses can only be accessed from these roads. In some 
cases the access to one business is through the parking lot of another.

\subsection{Spatial Character}

The most striking common spatial characteristics of the interstate villages are the low density sprawling appearance, wide roads with vast amounts of parking surface, a course grain with larger isolated buildings, and very little vegetation of any kind (vegetation that may be present is token decoration and not used to create or reinforce a spatial structure in the landscape). Each building strives to be a self-contained environment, trying to out-compete the same business type next door and oblivious to any sense of a village context. The architectural styles follow a corporate formula so that the buildings of a hotel chain, for example, look the same wherever you are. Because of the large spaces between buildings there is poor visual containment and the village environment is not structured to facilitate a rich experiential journey such as Cullen [22] suggests with his process of 'serial vision' through a 'townscape'. The proliferation of strip signage mentioned previously results in a visually chaotic landscape with considerably more information than one can take in moving at automobile speeds. There is no public space, because there is no public to use it. There are no sidewalks, with the entire environment designed exclusively for automobile movement. Because there is no subsurface stormwater management system in the villages the wide main road is flanked by large ditches that probably handle the stormwater adequately but visually are poorly integrated into the corridor. In spite of an overall impression of a messy, chaotic and patchwork landscape, the traveler likely finds comfort in the familiarity that comes with the similarity of the interstate villages. The same businesses populate every village with their ubiquitous corporate iconography and formulaic environments. In spite of the fact that this description contradicts our idea of what constitutes 'place', it allows the traveler to understand the village landscape and to navigate it with confidence.

Interestingly, the sprawling, placeless feel of the interstate villages was in sharp contrast to the environments in many of the towns that had small town main streets and tree lined residential ways.

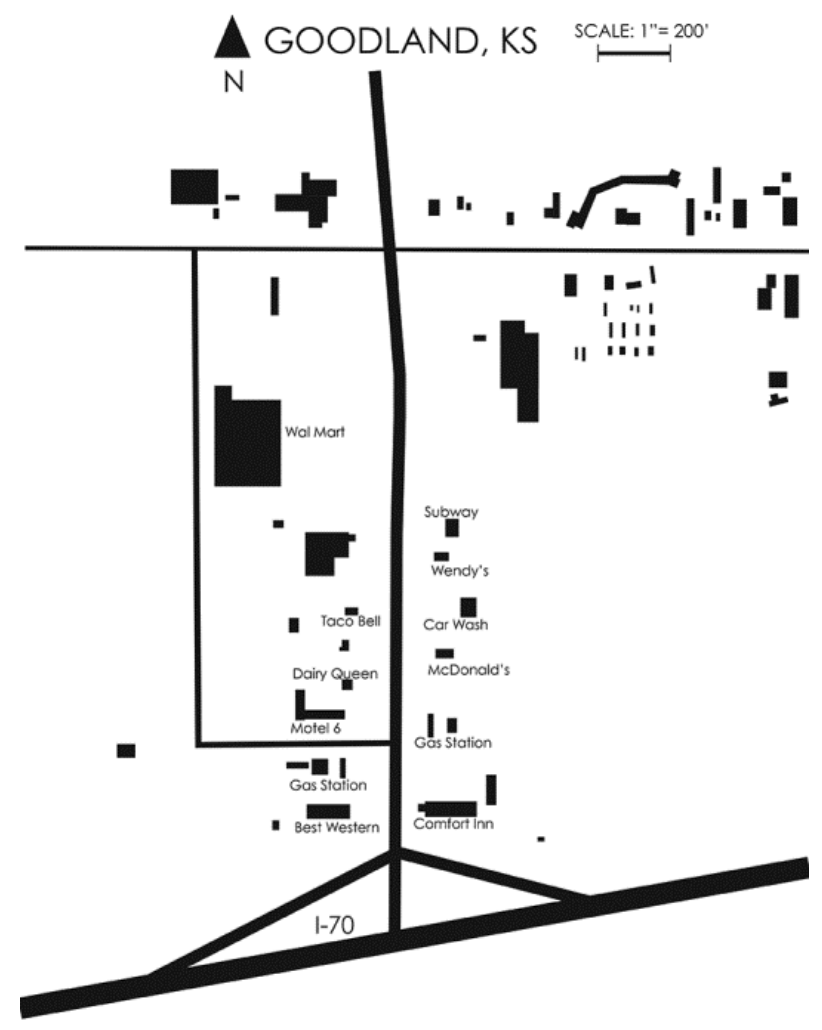

Figure 3. Development on one side of I-70. Drawing by Andrew Bernard and author

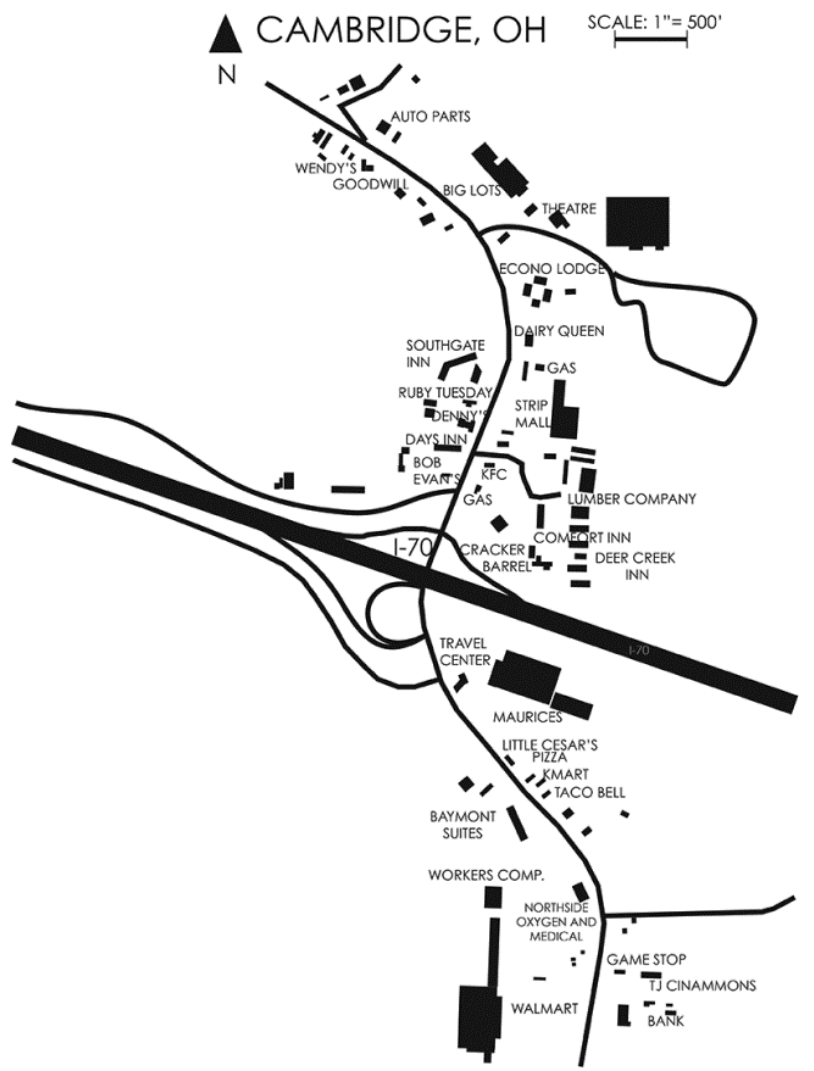

Figure 4. Development on both sides of I-70. Drawing by Andrew Bernard and author 


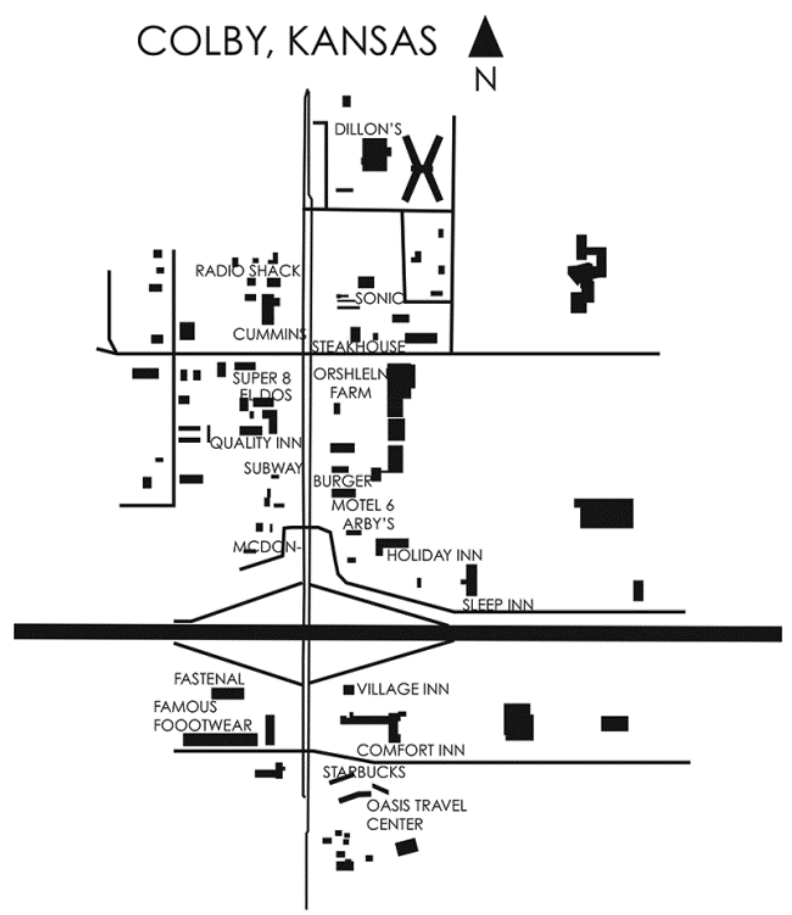

Figure 5. Perpendicular roads Drawing by Andrew Bernard and author

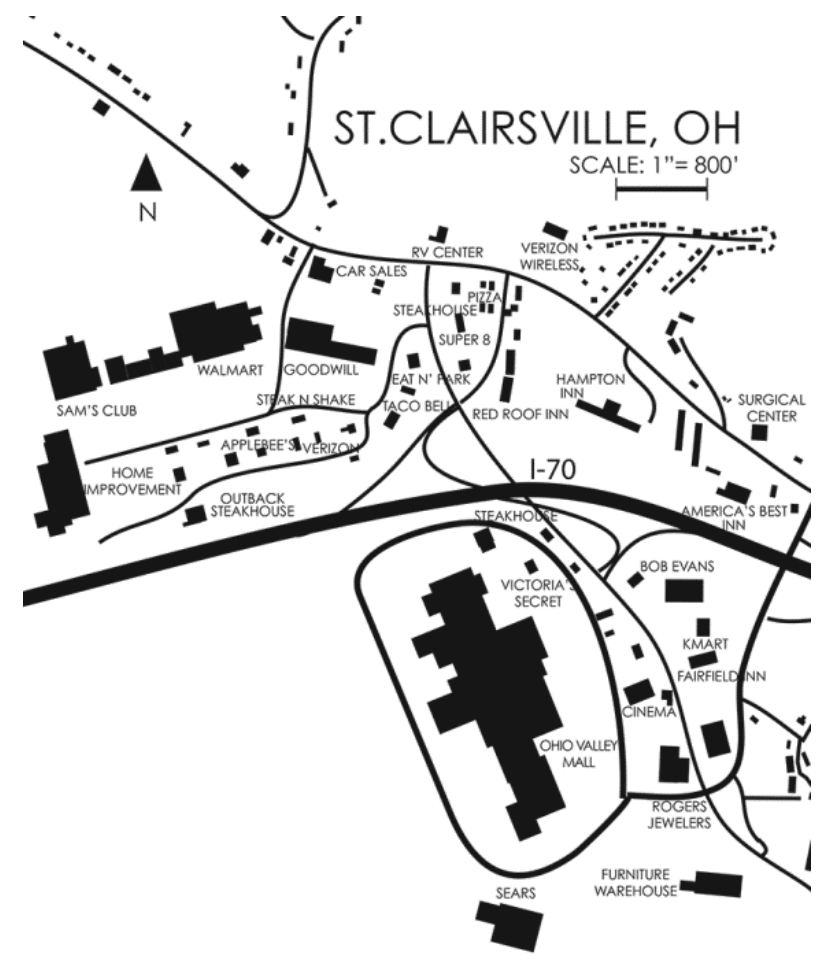

Figure 6. Interstate village as a regional center. Drawing by Andrew Bernard and author

\subsection{Regional Expression}

Norris [15] concluded that "Roadside homogeneity in American culture is a common assumptive slur that does not survive close scrutiny. The commercial cluster at an interstate exit does follow norms of form, scale, composition and structure, but in detail its repertoire is endless and bears witness to the regional variation which pervades and enriches American mass culture" (p.31). Is some form of regional or local expression irrepressible regardless of how formulaic a built environment is, and does Norris's assertion have validity? For example, it is interesting that one can find a green chili cheeseburger at a McDonalds in New Mexico, and I suspect that the burger finds this kind of nuance at McDonalds outlets in other regions. Beyond subtle variations in cuisine are there other indicators of regional or local character in the interstate village? The Vermont report [16] suggested the potential for the interstate village to be a gateway to the adjacent town. In the villages sampled in this study there was little evidence of a gateway function. Colby Kansas is one exception, where the interstate village has a visitors' center, and where the town's claim to be the 'oasis of the plains' is expressed by an artificial palm tree grove sculpture (Figure 8). Norris also observed the presence of some local businesses in villages as evidence of regional variation. This was borne out to some degree, but the local businesses, in attempting to compete with their corporate neighbors, try to look and feel more like them rather than anything associated with the town or the region. Any architectural variation from village to village was due to the evolution of the corporate architectural styles, rather than regional influence. Only one hotel chain, Best Western, gave a superficial nod to local character in a couple of the villages. For example, in Burlington, $\mathrm{CO}$, one of the town attractions is a carousel built in Denver in the early part of the twentieth century that was subsequently moved to the Burlington fair grounds. The carousel is housed in an octagonal structure, and the Best Western in the interstate village, named the 'Carousel Inn and Suites', incorporated an octagonal appendage at one end of their building that serves as the restaurant. While even these kinds of gestures were not common in the villages sampled, when they did occur it was at a similar superficial level. The overwhelming sense is that as physical environments the interstate villages are much more a part of the interstate landscape than of the towns to which they are connected.

\subsection{The Towns' Perspectives}

Most of the interstate villages in the sample were developed between the mid 1960s to the early 1980s and they continue to develop. Multiple developers, some of them local, have been involved in each village, with the town being active in the development in some cases. Agreements have been reached with the town and the local utilities to provide and maintain infrastructure to the villages in much the same way as for any development. Most of the towns feel that the interstate village is indeed a gateway to the town, and they feel that the presence of the village is a benefit. They enjoy the significant tax base and the economic advantages offered by the villages. Notwithstanding the observed disconnect between the interstate villages and the towns, the responses from town managers' offices indicated that they have very 
good relations with the interstate village businesses. While there was acknowledgment that the interstate villages have created a different business dynamic than existed previously, particularly concerning growth and development in the downtowns, the overall economic benefit to the rural areas has been regarded as very positive, and the towns continue to promote growth and development at their interchanges.

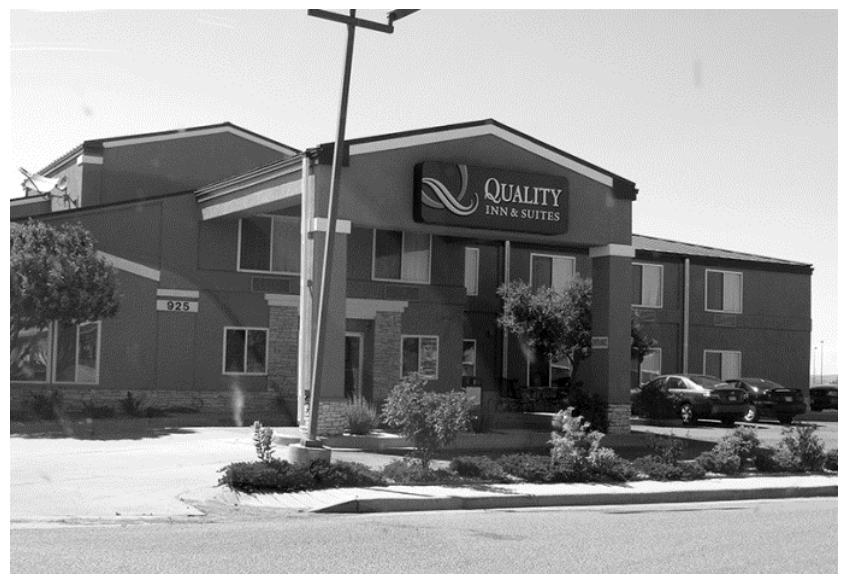

Figure 7. Corporate architecture and 'decorative' planting.,Limon, CO. Photo by author

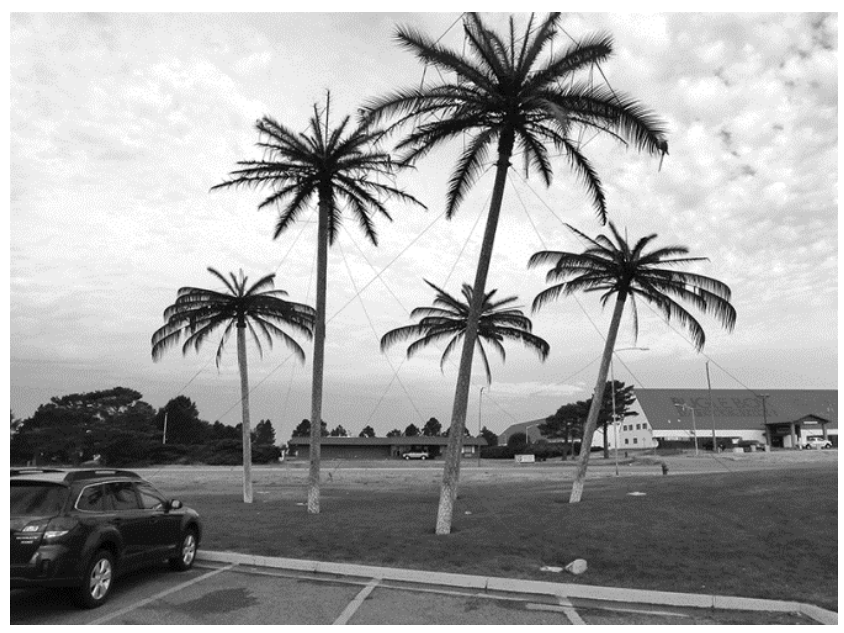

Figure 8. Artificial palm setting at the 'Oasis of the Plains', Colby, KS. Photo by author

\section{Summary and Conclusions}

The observations of the fourteen interstate villages in this study indicate that the village is a distinct landscape type with a definable structure, composition and character. This part of the hypothesis appears to be borne out. The villages tend to be linear in form, along an axis that is perpendicular to the interstate. The buildings and spaces of the village are sited in such a way that they do not establish relationships with one another, but rather are a very loose, unconsolidated collection that present themselves as isolated islands. The most predominant visual element in the villages are free-standing signs placed along the roadway. The village landscape is designed exclusively to be accessed and experienced in the automobile.

While there is not a total absence of regional presence in the interstate villages, we cannot say that they have a regional identity, nor that authentic ecological or cultural regional expression is present. Token and superficial 'theme park' gestures are the norm. Regardless of the political relationships that the villages have with their adjacent towns, or whether local developers have been involved, they appear to maintain themselves as separate landscapes with a distinct character that is common to the language of the interstate experience rather than to any region. The hypothesis concerning irrepressible regional identity in the villages, as suggested by Norris, did not prove to be true in this study.

For those who study design and the human landscape, the interstate village poses a dilemma. There is nothing about the villages that suggests good urban design and planning. In fact, they would appear to be the epitome of poor urban development practices. In spite of this the villages seem to be flourishing and growing, and economically successful. They are service landscapes that fill a very important need and function within the interstate system. Whether or not one might think that the villages are good urban landscapes, in accordance with theoretical propositions of what constitutes good design and planning, the similarity, familiarity and hence comfort that they offer for travelers on the interstate is undeniable. Certainly, the villages could fulfill all of their important functions and still be conceived in what one might imagine as more attractive and compelling environments, but what is the incentive to do this? Village developers and corporate chains that locate there would not likely gain greater profit from such an endeavor. Perhaps it would be better to accept the villages for what they are, and to acknowledge that they have a particular value, and may even be seen as 'places' within the unique interstate landscape.

Even though I-70 is the first interstate highway with the first construction beginning in 1956, most of the interstate villages have been developing only over the last thirty years. The village is a very young phenomenon. It is quite possible that, over time, as the villages grow they may begin to develop their own unique identities, just as railroad towns developed theirs. As the villages and the adjacent towns grow into each other, how will mutual influences change them?

One of the purposes of this limited study was to assess whether the findings would indicate that further study in different regions is warranted. It became clear that in spite of the fact that the transect covered approximately 1700 miles, much of it fell along what we describe as the great plains and the mid-west, and there was less dramatic regional variation than one might expect over such a long distance. Further study could indicate whether the conclusions of this study are 'universal', or whether significant variation in the village layouts and regional expression occurs along other north/south and east/west transects. 


\section{REFERENCES}

[1] H.E. Moon, The Interstate Highway System, Chicago: Association of American Geographers, 1994.

[2] Tom Lewis, Divided Highways: Building the Interstate Highways: Transforming American Life, New York: Penguin Group, 1997.

[3] Dan McNichol, The Roads That Built America: The Incredible Story of the U.S. Interstate System, New York: Sterling Publications, 2005.

[4] Dianne Perrier, Onramps and Overpasses: A Cultural History of Interstate Travel, Gainsville: University Press of Florida, 2009.

[5] John Murphy, The Eisenhower Interstate System, Chelsea House Publications, 2009.

[6] H. E. Moon, Interstate Highway Interchanges as Instigators of Nonmetropolitan Development, Transportation Research Record, 11(25), 8-14, 1987.

[7] M. G. Boarnet, Highways And Economic Productivity: Interpreting Recent Evidence, Journal of Planning Literature, 11(4), 476-486, 1997.

[8] H. B., Gamble, D. L., Raphael, D. H. Sauerlender, Direct and Indirect Economic Impacts of Highway Interchange Development, Highway Research Record, 149, 42-55, 1966.

[9] R. D. Twark, A Predictive Model Of Economic Development At Non-Urban Interchange Sites On Pennsylvania Interstate Highways, University Park: Pennsylvania State University, 1967.

[10] P. D. Cribbins, W. T. Hill, H. O. Seagraves, Economic Impact of Selected Sections of Interstate Routes on Land Value and Use, Highway, Research Record 75, HRB, National Research Council, Washington, D.C., 1-30, 1965.

[11] R. Briggs, The Interstate Highway System And Development
In Nonmetropolitan Areas, Transportation Research Record, 8(12), 9-12, 1981.

[12] R. W., Eyerly, R. W. Twark, R. H. Downing, Interstate Highway System: Reshaping The Non-Urban Areas Of Pennsylvania, Transportation Research Record, 11(25), 1-14. 1987.

[13] C. R. Humphrey, R. R. Sell, The Impact Of Controlled Access Highways On Population Growth In Non-Metropolitan Communities 1940-1970, (Working Paper No. 1975-03), University Park: Pennsylvania State University, Population Issues Research Office, 1975.

[14] F. I. Thiel, Highway Interchange Area Development, Highway, Research Record 96, HRB, National Research Council, Washington, D.C., 2-5, 1965.

[15] Darrell A. Norris, Interstate Highway Exit Morphology: Non-metropolitan Exit Commerce on 1-75, The Professional Geographer 39 (1), 23-32, 1987.

[16] Vermont Department of Housing and Community Affairs, Vermont Interstate Interchange Planning and Development Design Guidelines, 2004.

[17] Francis John Haverfield, Ancient Town Planning, London: Oxford University Press, 1913.

[18] Giulio Magli, On The Orientation Of Roman Towns In Italy, Oxford Journal of Archaeology 27(1), 63-71, 2008.

[19] E. Relph, Place and Placelessness, London: Pion Ltd., 1976.

[20] Howard Kunstler, The Geography of Nowhere, New York: Simon \& Schuster, 1993.

[21] J.B. Jackson, Roads Belong in the Landscape, Landscape in Sight, Helen Lefkowitz Horowitz, ed., New Haven: Yale University Press, 1997.

[22] Gordon Cullen, The Concise Townscape, London: Architectural Press, 1964. 